\title{
Clinical and biological characteristics of Ureaplasma urealyticum induced polyarrthritis in a patient with common variable hypogammaglobulinaemia
}

\author{
R R Lehmer, B S Andrews, J A Robertson, E J Stanbridge, L de la Maza, G J Friou
}

\begin{abstract}
Persistent infectious polyarthritis caused by Ureaplasma urealyticum in a patient with common variable hypogammaglobulinaemia is described. The patient developed a symmetrical, destructive polyarthritis and tenosynovitis associated with a markedly depressed synovial fluid glucose concentration and characteristic soft tissue abscesses. The ureaplasma organism developed resistance to multiple antibiotics and persisted for five years. The organism was identified repeatedly in many joints by culture, confirmed by DNA hybridisation, and mycoplasma-like structures were shown in synovial tissues by electron microscopy.
\end{abstract}

Hypogammaglobulinaemia has been associated rarely with an infectious arthritis due to organisms of the Mycoplasmataceae family, which includes the Mycoplasma and Ureaplasma genera. Ureaplasma urealyticum has been recognised as a cause of septic polyarthritis in four patients ${ }^{1-4}$ and Mycoplasma species in three ${ }^{5-7}$; on each occasion the infectious process responded well to antibiotics and replacement gammaglobulin. One patient ${ }^{2}$ with $U$ urealyticum septic arthritis subsequently developed recurrent arthritis, antibiotic resistance, and was treated with specific hyperimmune antiureaplasmal serum. ${ }^{8}$ Although transient polyarthritis has been well reported following acute $M$ pneumoniae infection, the organism has not been isolated from synovial fluid in these patients. ${ }^{9}$

Culture positive septic arthritis due to Mycoplasmataceae, as in this patient with $U$ urealyticum septic arthritis, has not previously been associated with a reduction in synovial fluid glucose, though there is one previous report of a patient with reduced synovial fluid glucose, hypogammaglobulinaemia, and culture negative polyarthritis with mycoplasma-like organisms shown in synovium by electron microscopy. ${ }^{10}$ Further, the use of $\mathrm{cDNA}$ probes to identify the organism and the rapid development of antibiotic resistance has not previously been reported.

\section{Case report}

A 38 year old white man was well until the age of 23 when he developed recurrent sinopulmonary infections, which were treated with antibiotics. At age 25 he had had two episodes of non-gonococcal urethritis, each treated with tetracycline. At age 28, a diagnosis of common variable hypogammaglobulinaemia was made, based on an IgG concentration of $0.25 \mathrm{~g} / 1$ (normal 7·23-16.85 $\mathrm{g} / \mathrm{l}$ ), an undetectable serum IgA concentration (normal 0.69-3.82 g/l), and an IgM concentration of $0.072 \mathrm{~g} / \mathrm{l}$ (normal 0.63-2.77 $\mathrm{g} / \mathrm{l}$ ). Monthly intramuscular gammaglobulin treatment over the next six years led to a reduction in the number of respiratory tract infections.

At age 34 the frequency of gammaglobulin treatment was reduced and six months later, in March 1984, he developed acute, symmetrical, inflammatory polyarthritis affecting the small joints of the hands and feet, ankles, knees, hips, wrists, elbows, and shoulders, associated with tenosynovitis of the extensor tendons of ankles and wrists. Serum immunoglobulin concentrations remained low. The white cell count in synovial fluid from the right knee was $15 \times 10^{9} / 1$, with $80 \%$ polymorphonuclear leucocytes, $18 \%$ monocytes, and $2 \%$ lymphocytes. Glucose was profoundly depressed at $0.05 \mathrm{~g} / \mathrm{l}$, with a simultaneous serum concentration of $1.25 \mathrm{~g} / \mathrm{l}$; this pattern persisted. Smears and cultures for aerobic and anaerobic bacteria, mycobacteria, and fungi were negative. A diagnosis of polyarthritis associated with hypogammaglobulinaemia was made, and treatment with intravenous gammaglobulin ( $5 \%$ Gamimune, Cutter Biol.) and indomethacin was started. When the arthritis failed to improve he was transferred to the University of California Irvine Medical Center. Intravenous gammaglobulin was further increased to $200 \mathrm{ml}$ weekly, without a change in the synovitis.

Synovectomy of the right wrist and extensor tendon sheaths was performed in mid-September 1984, with radiographs of the wrist showing progressive destructive changes compatible with rheumatoid arthritis. Mycoplasma cultures were performed $^{11}$ and, within 24 hours, Ureaplasma urealyticum was isolated and subsequently identified as serotype $10 .^{12}$ Tetracycline (2 $\mathrm{g} /$ day intravenously) was instituted, and within one week the synovitis had improved significantly. After a further eight days, however, it flared again. Erythromycin (4 g/day intravenously) and streptomycin ( 2 g/day intramuscularly) were then substituted with a similar initial marked clinical response, but two weeks later joint symptoms flared again. Doxycycline (100 mg every 12 hours intravenously) and gentamicin (100 mg every eight hours intravenously) were then used, based on initial antibiotic sensitivities (table). ${ }^{13}$ Although this treatment led to slight clinical improvement, persistent pain and progressive destruction of the right knee resulted in an open synovectomy with continued isolation of the organism from synovial fluid despite antibiotics given intravenously. From mid-October 1984 until midFebruary 1985 treatment was continued with intravenous doxycycline, but the synovitis was 
Antibiotic sensitivities (minimum inhibitory concentration) of ureaplasma isolates

\begin{tabular}{lcc}
\hline Antibiotic & $\begin{array}{l}\text { Initial aspirate } \\
(\mu g / m l)\end{array}$ & $\begin{array}{l}\text { Thigh abscess } \\
(\mu g / m l)\end{array}$ \\
\hline Doxycycline & 8 & 8 \\
Tetracycline & 128 & 128 \\
Erythromycin & 256 & 256 \\
Rosaramicin & 1 & $128^{*}$ \\
Chloramphenicol & 32 & 32 \\
Amikacin & 128 & 128 \\
Gentamicin & 32 & 32 \\
Kanamycin & 32 & 32 \\
Streptomycin & 64 & 64 \\
Spectinomycin & 64 & 64 \\
Norfloxacin & 8 & 8
\end{tabular}

* Simultaneous synovial fluid minimum inhibitory concentration was $1 \mu \mathrm{g} / \mathrm{ml}$.

progressive, leading to destruction of both ankles, right wrist, left elbow, left hip, and rupture of extensor tendons to his toes. Persistent infection was associated with a continuing purulent drainage from the right knee. In addition, he developed multiple subcutaneous and deep nodular lesions, predominantly over extensor surfaces of affected limbs, which coalesced to form large culture positive soft tissue abscesses.

In April 1985 the patient was readmitted with active synovitis with similar synovial fluid findings and antibiotic sensitivities. Because of clinical deterioration the macrolide antibiotic rosaramicin (Schering Pharmaceuticals) was started at $2 \mathrm{~g} /$ day orally. Within seven days the synovitis had improved significantly. Rosaramicin was continued until clinical remission in July 1985. Rosaramicin was restarted in December 1985, however, when the synovitis recurred with the organism reisolated from the left shoulder. On this occasion only minimal clinical improvement occurred, with progression of synovitis and development of a large abscess in the right thigh containing $U$ urealyticum serotype 10, now resistant to rosaramicin. A simultaneous aspirate from the right elbow, however, showed that the same Ureaplasma serotype remained sensitive to rosaramicin at the initial minimum inhibitory concentration (table). As two rosaramicin minimum inhibitory concentrations were obtained the antibiotic was continued until July 1987, but owing to an increase in hepatic enzymes the dosage was reduced to $1.5 \mathrm{~g} /$ day. Over this period low grade synovitis persisted. In March 1988 a marked exacerbation led again to reinstitution of rosaramicin with repeated isolations of the organism. Rosaramicin was finally stopped in June 1988 without any further severe exacerbations.

After the initial isolation of the organism, studies were undertaken to characterise the pathological process. Routine histopathology of synovium was non-diagnostic, showing nonspecific acute and chronic inflammation without evidence of granulomata or lymphoid aggregation. Mycoplasma-like organisms were putatively demonstrated by transmission electron microscopy of both synovium, where they appeared as sphere-like structures adhering to the surface membrane of synovial lining cells, and of an ultracentrifuge pellet of broth cultured organisms (fig 1). Further, an 867 bp cDNA probe derived from the $23 \mathrm{~S}$ rRNA operon of

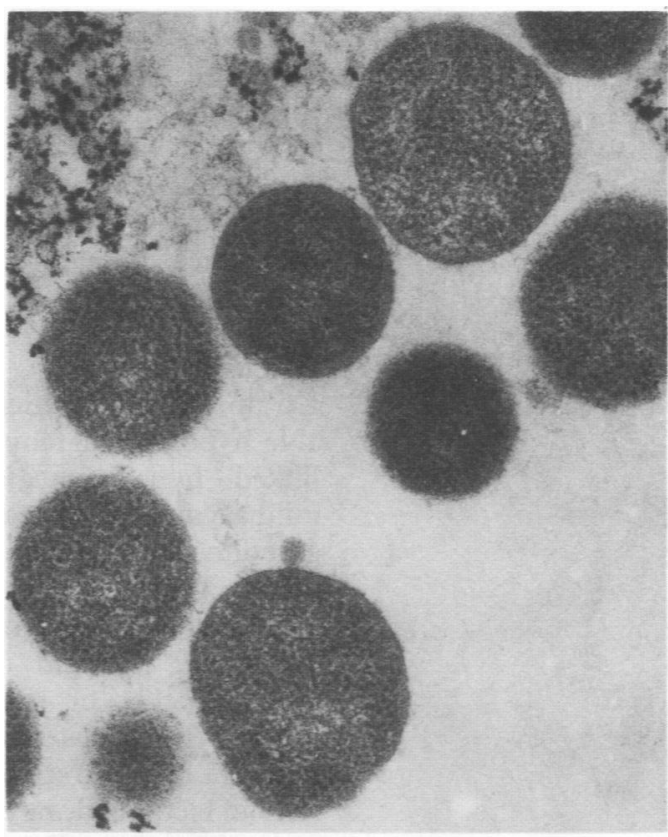

Figure 1 Transmission electron micrograph of ureaplasma organisms from an ultracentrifuge pellet of culture broth containing synovium.

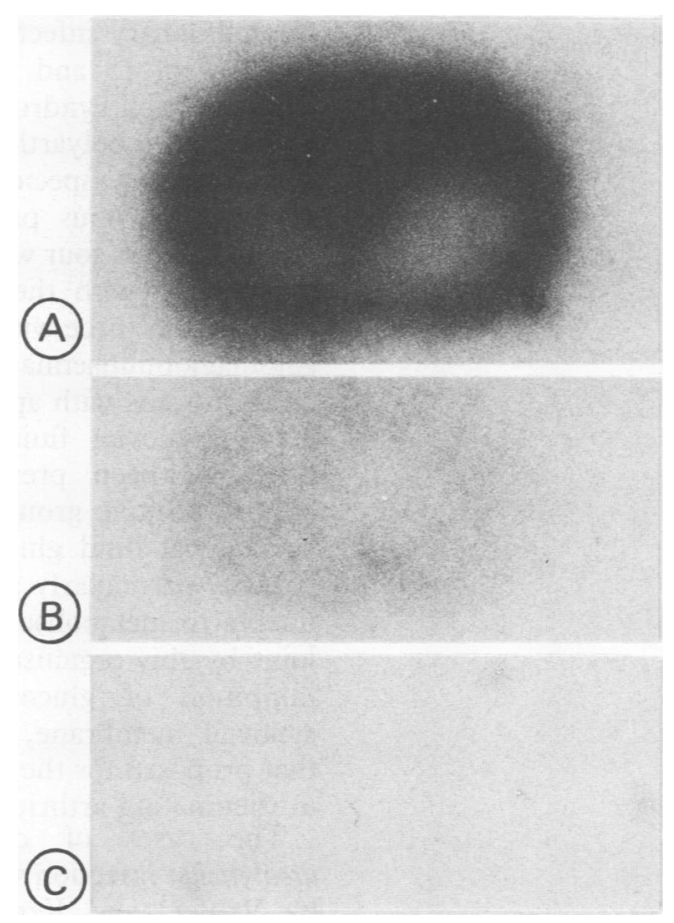

Figure 2 Dot-blot hybridisation of DNA extracted from a synovial fluid sample with an 867 bp Mycoplasma hyorhinis probe. ${ }^{14}(A)$ Control blot of DNA from D98 human cell line heavily infected with $M$ hyorhinis $\left(10^{6}\right.$ colony forming units/ml). (B) Synovial fluid leucocyte DNA extract from a Ureaplasma urealyticum culture positive joint. (C) Culture negative synovial fluid leucocyte DNA extract from a patient with degenerative joint disease. The lesser intensity of the test blot can be expected owing to the inexact homology of

$M$ hyorhinis and $U$ urealyticum ribosomal genes and the indeterminate number of organisms. $10 \mu \mathrm{g}$ of DNA were used in each sample.

Mycoplasma hyorhinis, which has been used to detect contaminating mycoplasmas in tissue cultures, ${ }^{14}$ was used in slot blot analysis to hybridise ureaplasma DNA extracted from synovial fluid leucocytes (fig 2). Analysis of synovial fluid DNA in this patient did not provide more sensitivity than culturing this organism under optimal laboratory conditions. 
Further, growth of this ureaplasma was inhibited by a $1 \mathrm{mmol} / \mathrm{l}$ concentration of manganese, and the erganism contained a DNA sequence that hybridised to the tetM sequence from Streptococcus agalactiae - a feature of tetracycline resistant strains of $U$ urealyticum. ${ }^{15}$ No plasmids have been isolated in cloned strains of this organism.

\section{Discussion}

Up to $25 \%$ of patients with common variable hypogammaglobulinaemia or Bruton's sex linked hypogammaglobulinaemia develop a mild asymmetric polyarthritis. Regular gammaglobulin replacement treatment usually produces prompt resolution of the synovitis. ${ }^{10}$ If immunoglobulin deficiency has not been previously reported the clinical picture may resemble that of rheumatoid arthritis. ${ }^{5}$ The arthritis is associated with low serum immunoglobulin concentrations, absence of IgM rheumatoid factor and, rarely, subcutaneous nodules or bone erosions. Destructive polyarthritis with deformities has not been previously reported. In common variable hypogammaglobulinaemia there is usually a preceding history of recurrent sinopulmonary infections, with onset between the ages of 15 and 35, and, less commonly, malabsorption syndrome.

Infectious polyarthritis due to Mycoplasma and Ureaplasma species has been clearly reported in seven previous patients with hypogammaglobulinaemia, four with onset in childhood and presumably with the sex linked form of the disease, and three with common variable hypogammaglobulinaemia. Severe synovitis resolved in all patients with appropriate antibiotic treatment. Synovial fluid glucose concentrations have not been previously reported in this culture positive group. The marked reduction in synovial fluid glucose is significant in this patient, particularly as Ureaplasma species are unable to metabolise glucose. Infection of the joint by this organism might have resulted in inhibition of glucose transport across the synovial membrane, a mechanism similar to that proposed for the low synovial fluid glucose in rheumatoid arthritis.

The cases of disseminated Ureaplasma urealyticum infection with polyarthritis reported by Vogler $^{3}$ and Kraus, ${ }^{4}$ and of Mycoplasma pneumoniae by Johnston ${ }^{6}$ were also associated with soft tissue abscesses, with early lesions mimicking rheumatoid nodules.

We showed the presence of mycoplasma-like organisms by electron microscopy and mycoplasma DNA sequence by cDNA hybridisation of DNA extracted from synovial fluid cells. Polynucleotide probes may provide an alternative and more sensitive method for the detection of organisms within the joint of patients with polyarthritis, where conventional culture techniques are negative. Additionally, with advances in molecular biological techniques, amplification of small amounts of DNA from suspected infectious agents should be possible using the polymerase chain reaction. These techniques may havel immediate application in patients with culture negative gonococcal arthritis, reactive arthritis and, possibly, in some patients with rheumatoid arthritis, where mycoplasma have long been suspected, but never proved, as pathogenic agents. ${ }^{16}$

Development of resistance to multiple antibiotics by ureaplasma is extremely rare, with only two previous reports in patients with hypogammaglobulinaemia and persistent $U$ reaplasma urealyticum infections-one with urethritis, ${ }^{17}$ the other with recurrent arthritis. ${ }^{8}$ There are no previous reports of different sensitivities to an antibiotic in simultaneously isolated organisms of the same strain, either in patients with infections due to Mycoplasmataceae or any other organism.

This case illustrates the need to consider mycoplasma infection in a patient with inflammatory arthritis and immunoglobulin deficiency. Determination of antibiotic sensitivities should be carefully repeated when there is a failure to respond or recurrence of infection while receiving antibiotics. Septic arthritis due to mycoplasmas may represent another cause of markedly depressed synovial fluid glucose. Similarities between mycoplasma polyarthritis and rheumatoid arthritis support the hypothesis that these organisms might have an aetiological role in the pathogenesis of some cases of rheumatoid arthritis.

1 Stuckey M, Quinn P A, Gelfand E W. Identification of Ureaplasma urealyticum in a patient with polyarthritis. Lancet 1978; ii: 917-20.

2 Webster A D B, Taylor-Robinson D, Furr P M, Asherson G L. Mycoplasma (ureaplasma) septic arthritis in hypogammaglobulinaemia. BMF 1978; i: 478-9.

3 Vogler L B, Waites K B, Wright $\mathbf{P}$ F, Perrin J M, Cassel G $\mathbf{H}$. Ureaplasma urealyticum polyarthritis in agammaglobulinemia. Pediatric Infectious Disease 1985; 4: 687-91.

4 Kraus V B, Baraniuk J N, Hill G B, Allen N B. Ureaplasma urealyticum septic arthritis in hypogammaglobulinaemia. f R heumatol 1988; 15: 369-71.

5 Taylor-Robinson D, Gumpel J M, Hill A, Swannell A J. Isolation of Mycoplasma pneumoniae from the synovia fluid of a hypogammaglobulinaemic patient in a survey of patients with inflammatory polyarthritis. Ann Rheum Dis 1978; 37: 180-2.

6 Johnston C L W, Webster A D B, Taylor-Robinson D Rapaport G, Hughes G R V. Primary late-onset common variable hypogammaglobulinaemia associated with inflammatory polyarthritis and septic arthritis due to Mycoplasma matory polyarthritis and septic arthritis due to $M$

7 So A K L, Furr P M, Taylor-Robinson D, Webster A D B. Arthritis caused by Mycoplasma salivarium in hypogammaglobulinaemia. BMf 1983; 286: 762-3.

8 Taylor-Robinson D, Furr P M, Webster A D B. Ureaplasma urealyticum infection in the immunocompromised host. Pediatric Infectious Disease 1986; 5: S236-8.

9 Hernandez L A, Urquhart G E, Dick W C. Mycoplasma pneumoniae infection and arthritis in man. BMF 1977; ii: 14-16.

10 Webster A D B, Loewi G, Dourmashkin R D, Golding D N, Ward D J, Asherson G L. Polyarthritis in adults with hypogammaglobulinaemia and its rapid response to hypogammaglobulinaemia and its rapid response

11 Robertson J A. Bromothymol blue broth: improved medium for detection of Ureaplasma urealyticum (T-strain mycoplasma). F Clin Microbiol 1978; 7: 127-32.

12 Stemke G W, Robertson J A. Modified colony indirect epifluorescence test for serotyping Ureaplasma urealyticum and an adaptation to detect common antigenic specificity. f Clin Microbiol 1981; 14: 582-4.

13 Robertson J A, Coppola J E, Heisler O R. Standardised method for determining antimicrobial susceptibility of strains of Ureaplasma urealyticum and their response to strains of Ureaplasma urealyticum and thir response to tetracycline, erythromycin, and
Agents Chemother 1981; 20: 53-8.

14 Gobel U B, Stanbridge E J. Cloned mycoplasma ribosomal RNA genes for the detection of mycoplasma contamination RNA genes for the detection of mycoplasma
in tissue culture. Science 1984; 226: 1211-3.

15 Robertson J A, Stemke G W, Maclellan S G, Taylor D E. Characterization of tetracycline-resistant strains of Ureaplasma urealyticum. $\mathcal{J}$ Antimicrob Chemother 1988; 21: plasma

16 Cassell G H, Cole B C. Mycoplasma as agents of human disease. NEngl f Med 1981; 304: 80-9.

17 Taylor-Robinson D A, Furr P M, Webster A D B Ureaplasma urealyticum causing persistent urethritis in a patient with hypogammaglobulinaemia. Genitourin Med 1985; 61: 404-8. 